\title{
Desafios da gestão escolar: concepções e práticas
}

\section{The school management challenges: concepts and practices Los retos de gestión escolar: conceptos y prácticas}

É com satisfação que trazemos a público mais um número da Revista Brasileira de Política e Administração da Educação. Como tradicionalmente vem ocorrendo a cada ano, trata-se do dossiê de 2015 cujo tema são os Desafios da Gestão Escolar abordados nas mais distintas perspectivas.

Os artigos que o constituem originaram-se da confluência de diversas redes de pesquisadores da área da Educação tecidas a partir de variadas origens. Redes que germinaram em eventos científicos em ricos momentos de discussão de comunicações sobre o tema da gestão educacional, redes fundadas na circulação da produção científica e redes de pesquisa. É um dossiê que traz um aporte teórico consistente e contribuições de pesquisa empírica em diferentes contextos referidos seja à educação brasileira, seja à portuguesa. A empiria é variada uma vez que os dados ora foram coletados em escolas públicas municipais, ora em escolas públicas estaduais. Os textos são construídos a partir de diferentes espaços profissionais, seja pelo trato de dados estatísticos iluminados pelo conhecimento teórico-prático da gestão, seja na interação universidade e escola pública, seja mediante a reflexão acerca de experiência de gestão em rede pública municipal de ensino.

O artigo Liderança na gestão escolar, de autoria de Jorge Adelino Costa (da Universidade de Aveiro - Portugal) e Patrícia Castanheira (da Universidade de Brighton - Inglaterra), situa-se no campo da análise organizacional. Discorre acerca da evolução histórica das concepções sobre liderança, debatendo as dimensões que caracterizam o exercício da liderança em instituições escolares. É uma contribuição que traz consistente quadro teórico e que acena para a importância do tema na formação de gestores escolares.

Segue o artigo Formação continuada de diretores escolares fundamentado em pesquisa colaborativa entre universidade e rede pública de ensino, organizado por Yoshie Leite e Vanda Lima (ambas da FCT/UNESP, Campus de Presidente Prudente), que considera saberes e práticas do diretor escolar/equipe gestora. É um artigo que traz importante contribuição metodológica, além dos achados da pesquisa-ação-participante realizada em rede pública do estado de São Paulo. Em continuidade encontra-se $A$ construção da profissionalidade do gestor escolar: 
concepções e práticas, artigo que discorre acerca da profissionalidade do gestor construída no exercício da profissão e no enfrentamento dos desafios da prática, tendo como empiria a realidade do Ceará. Analisa os diferentes conteúdos envolvidos na gestão escolar, dentre os quais a organização curricular, as avaliações externas, o gerenciamento de recursos financeiros, frente aos quais o gestor se situa no enfrentamento do grande desafio da construção identitária e dos processos de formação. Foi elaborado por Elisangela Costa da UNILAB, Maria Socorro Lucena Lima e Maria Cleide da Silva Ribeiro Leite (ambas da UECE).

$\mathrm{O}$ artigo Gestão da aprendizagem em tempos de IDEB debate o impacto das avaliações em larga escala no trabalho docente, focalizando a análise nos dados fornecidos pelo questionário do professor da Prova Brasil 2011. As suas autoras, Sofia Lerche Vieira (UNINOVE e UECE), Eloisa Vidal (UECE) e Jaana Flavia Nogueira (MEC), analisam o perfil profissional dos professores, o trato que dão aos conteúdos curriculares, as dificuldades associadas, problematizando temas polêmicos e relevantes para o gestor escolar, especialmente relacionados a responsabilidades quanto aprendizagem dos alunos. No artigo que segue, Repercussões das politicas educacionais na organização escolar, Alice Botler (da UFPE) traz consistente quadro teórico discutindo as contradições entre autonomia e regulação frente à disponibilidade de tempo e ao uso que o gestor faz dele, numa abordagem que valoriza a racionalidade comunicativa, o diálogo e o trabalho integrado da equipe pedagógica. Desafios da gestão escolar também debate as múltiplas formas de regulação, valorizando como os gestores de escolas públicas de Porto Alegre se apropriam dos resultados do IDEB. É de autoria de Flávia Werle (da UNISINOS) e Janaina Audino (do Instituto JAMA de Porto Alegre). $\mathrm{O}$ artigo Agendas da educação básica, elaborado por Rosimar Esquinsani (UPF/ RS) e Carmem Lúcia da Silveira (Rede Municipal de Educação de Carazinho/ RS), analisa os vínculos entre a gestão escolar e a qualidade da educação em rede pública municipal do Rio Grande do Sul, destacando aspectos de ordem endógena e aspectos relacionados a estruturas burocráticas, formação docente e avaliações em larga escala.

Possibilidades de avanço democrático a partir de políticas educacionais é um artigo elaborado por Dayani Madalena Costa e Luciane Szatkoski (Secretaria Municipal de Educação de Jacareí/SP) a partir da prática reflexiva de gestoras de rede municipal de São Paulo em sua tarefa de implantação do ensino fundamental, calcada na gestão democrática, na participação e na concepção de que a gestão seja capaz de constituir-se mediante processos de aprendizagem constante.

Graziela Abdian e Maria Eliza Oliveira (ambas da UNESP/Marília) evidenciam no artigo Gestão e qualidade da educação de escolas estaduais paulistas no 
contexto de indicadores de desempenho o quanto as escolas públicas de educação básica estão atualmente direcionadas para o alcance de resultados externos, priorizando sua face institucional e a hierarquização e reprodução de normas, embora tenham potencialidade de construção de seus modos específicos de funcionamento, e de gestão democrática.

Finalizando o presente número e, portanto, esse dossiê, encontra-se o artigo Das teorias das organizações à organização das teorias em que Luis Leandro Dinis (do Fórum Português de Administração Educacional) debate o mundo da gestão e o mundo da organização, problematizando e estabelecendo cruzamentos entre as teorias e as práticas que os movem. Questiona as teorias organizacionais e as possibilidades explicativas que os diferentes quadros teóricos possam aportar para a gestão escolar. É um trabalho que problematiza e desafia a gestão escolar frente aos conflitos e ambiguidades em que está imersa e que os próprios textos que compõem esta coletânea apresentam.

Desejamos a todos e todas um excelente proveito da leitura dos artigos aqui publicados e salientamos que estes refletem a importância que vem sendo dada à discussão a respeito da gestão escolar a partir da diversidade de desafios que tem suscitado.

Flávia Werle

Editora Associada

Alice Happ Botler

Editora Associada

Janete Maria Lins de Azevedo

Editora 